\title{
Sequelae after modified Fontan operation: postoperative haemodynamic data and organ function
}

\author{
R Kaulitz, I Luhmer, F Bergmann, B Rodeck, G Hausdorf
}

\begin{abstract}
Objective-To investigate the specific sequelae of the Fontan operation, and particularly the potential sequelae of chronically elevated systemic venous pressure.
\end{abstract}

Design-A retrospective analysis of clinical and haemodynamic data and evaluation of organ function in 80 surviving patients undergoing modified Fontan operation for various forms of underlying functionally univentricular hearts.

Patients-65 patients $(81 \%)$ who had undergone a total cavopulmonary anastomosis and 15 an atriopulmonary anastomosis. Follow up ranged from 12 to 106 months (mean 54 (SD 23) months).

Results -62 patients underwent postoperative cardiac catheterisation (mean systemic venous pressure $10.5(2.5) \mathrm{mm} \mathrm{Hg}$ and cardiac index $\left.3.1(0.7) 1 / \mathrm{min} / \mathrm{m}^{2}\right)$. Older age at operation was significantly correlated with both higher systemic venous pressure and lower cardiac index. Atrial arrhythmia was documented on Holter electrocardiogram in $17 \%$. Protein losing enteropathy (with abnormal $\alpha_{1-}$ antitrypsin clearance) was found in $2 / 80$ patients $(2 \cdot 5 \%)$. Ten patients had hypoproteinaemia, with a significantly higher incidence in patients after total cavopulmonary anastomosis and young age at operation. Liver function tests reflecting liver synthesis and metabolism were normal in all, whereas mild cholestasis was found in nearly $30 \%$-predominantly in patients with a cardiac index of $<31 / \mathrm{min} / \mathrm{m}^{2} \quad(P=0.045)$. Five patients $(6 \cdot 2 \%)$ developed atrial thrombosis. Coagulation factor analysis in 44 patients showed protein $\mathrm{C}$ deficiency in 11 (25\%); laboratory signs of activation of the coagulation system were found in four of these $(9 \%)$. None of the abnormal laboratory indices was significantly related to underlying cardiac malformation, postoperative systemic venous pressure, or follow up interval.

Conclusions-A high proportion of clinically asymptomatic patients had abnormal laboratory findings on mid-term follow up. Detailed evaluation of organ function is necessary to detect the need for further diagnostic procedures before clinical symptoms develop.

(Heart 1997;78:154-159)
Keywords: Fontan procedure; univentricular heart; protein losing enteropathy; thrombosis

Over the past two decades increasing numbers of patients with various forms of functionally univentricular hearts have undergone a modified Fontan operation as a definitive palliative procedure. In most series the recent overall mortality is less than $10 \% .{ }^{12}$ The early clinical results are encouraging and for most of the patients a much better functional state can be achieved compared to the preoperative status. As the 10 year survival is expected to be $80 \%$, regular evaluation of postoperative morbidity becomes more and more important.

Postoperative morbidity has been mainly focused on the need for reoperations, the incidence of postoperative arrhythmias, and the risk of right atrial thrombi and protein losing enteropathy. ${ }^{34}$ Late deterioration in functional status was found with longer periods of follow up but not in association with preoperative risk factors, suggesting that the Fontan state per se was the main risk factor for the declining functional status. ${ }^{1}$

We designed a retrospective study that included preoperative and postoperative haemodynamic variables and clinical and laboratory investigations to assess the potential mid-term sequelae of a modified Fontan operation.

\section{Methods}

PATIENTS

Between 1986 and 1994, 90 patients with various forms of functionally univentricular hearts underwent one of the modifications of the Fontan operation at our institution. For the 80 surviving patients included in this retrospective study, the preoperative morphological and haemodynamic data, as well as surgical data, are given in table 1 . Forty nine patients $(61 \%)$ presented with a complex form of a univentricular heart with left atrioventricular valve stenosis or atresia, common atrioventricular valve, or associated systemic and pulmonary venous abnormalities. Forty patients underwent an aortopulmonary shunt procedure during the neonatal period. A bidirectional Glenn anastomosis preceded the total cavopulmonary anastomosis in 12 patients.

Preoperative haemodynamic data showed a mean pulmonary artery pressure of $11.3 \mathrm{~mm}$ $\mathrm{Hg}$ (range 6 to $27 \mathrm{~mm} \mathrm{Hg}$ ). Pulmonary arteriolar resistance was calculated to be more than $2.5 \mathrm{U} / \mathrm{m}^{2}$ in 10 patients. 
Table 1 Patient characteristics $(n=80)$

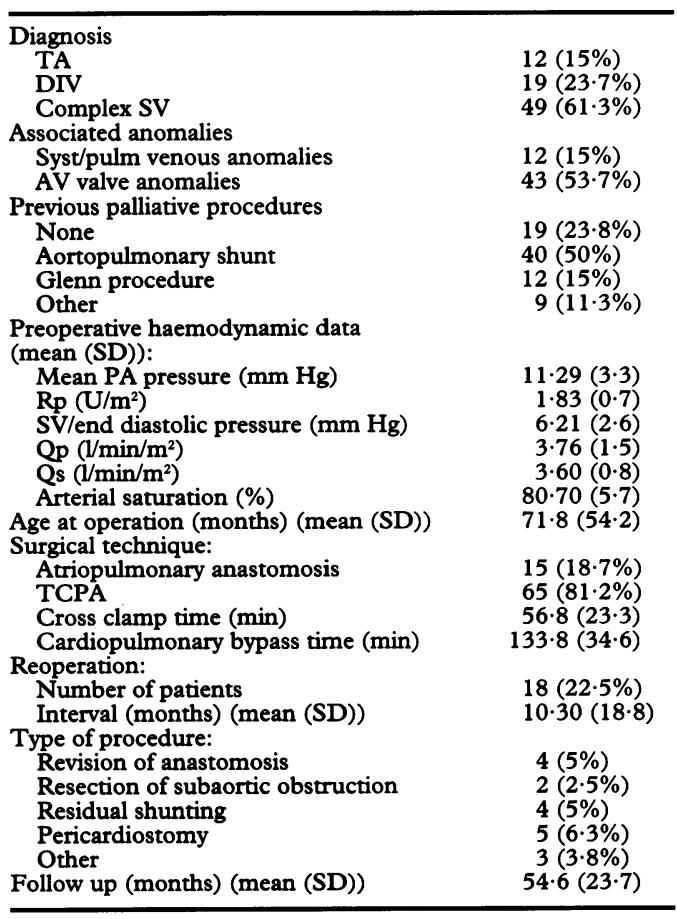

DIV, double inlet ventricle; PA, pulmonary artery; Qp, pulmonary blood flow; Qs, systemic blood flow; Rp, pulmonary arteriolar resistance; SV, single ventricle; Syst/pulm venous tricuspid atresia; TCPA, total cavopulmonary anastomosis.

Most patients (81\%) underwent a modified Fontan operation employing total cavopulmonary anastomosis. The age at operation varied from 7 to 244 months (mean 72 months), with 25 patients being younger than 36 months. Additional surgical procedures were performed in 28 patients $(35 \%)$. The reoperations performed in 18 patients (11 early, seven late) are summarised in table 1 . The follow up interval for all surviving patients ranged from 12 to 106 months (median 50 months). These patients are still under regular postoperative surveillance, including physical examination, electrocardiogram, Holter monitoring, and transthoracic cross sectional and Doppler echocardiography.

\section{CARDIAC CATHETERISATION}

Postoperative cardiac catheterisation was performed in 62 patients $(77 \%)$, with a mean postoperative interval of 31 months (range eight to 75 months). The patients underwent cardiac catheterisation under mild sedation. Pressures were recorded through a fluid filled catheter connected to a Statham strain gauge. The cardiac output was calculated based on the Fick principle.

Table 2 Postoperative haemodynamic data in 62 of the surviving patients

\begin{tabular}{lcc}
\hline & Mean (SD) & Range \\
\hline Interval (months) & $31 \cdot 12(18 \cdot 6)$ & 8 to 75 \\
Mean systemic venous pressure (mm Hg) & $10 \cdot 51(2 \cdot 5)$ & 6 to 19 \\
Mean PA pressure (mm Hg) & $10 \cdot 19(2 \cdot 2)$ & 6 to 17 \\
SV end diastolic pressure (mm Hg) & $5 \cdot 24(3 \cdot 1)$ & 2 to 20 \\
Qs (1/min/m ${ }^{2}$ ) & $3 \cdot 16(0 \cdot 7)$ & 1.9 to $4 \cdot 5$ \\
Arterial saturation (\%) & $93.4(4 \cdot 0)$ & 76 to 99 \\
\hline
\end{tabular}

PA, pulmonary artery; Qs, systemic blood flow; SV, single ventricle.
LABORATORY EVALUATION

In addition we introduced a laboratory protocol to evaluate organ function even in clinically asymptomatic patients. The detailed laboratory evaluation was performed as a part of the routine postoperative examination or at cardiac catheterisation. Variables included were those deemed appropriate to uncover haematological changes, to test liver function for synthesis and excretion, to evaluate the coagulation system, and to exclude potential risk factors for postoperative thromboembolic events (deficiency of plasminogen, antithrombin III, and protein C and S; pathological protein $\mathrm{C}$ resistance) or activation of the coagulation system. We also sought laboratory evidence of protein losing enteropathy, including hypoproteinaemia and hypalbuminaemia, lymphocytopenia, low immunoglobulin concentration (IgG), and deficiencies of fat soluble vitamins. The potential influence of preoperative, operative, and postoperative variables on clinical symptoms and laboratory indices was analysed.

STATISTICAL ANALYSIS

When appropriate data are expressed as mean (SD). All data were analysed using SPSS statistical software. Numerical data were analysed with the unpaired Student $t$ test; categoric data were analysed by using $\chi^{2}$ analysis. A $P$ value of $<0.05$ was considered significant. Stepwise logistic regression analysis was used to identify predictors of postoperative haemodynamic function and abnormal organ function.

\section{Results}

\section{POSTOPERATIVE HAEMODYNAMIC DATA}

Seventy seven per cent of the survivors (62 of 80) underwent postoperative cardiac catheterisation (table 2). Residual right to left shunting $(\leqslant 20 \%)$ with arterial desaturation was found in 10 patients (due to baffle fenestration in nine and to a residual defect within the suture line in one).

Comparing the patient groups with mean systemic venous pressure of $\leqslant 10 \mathrm{~mm} \mathrm{Hg}$ (37 patients) and $>10 \mathrm{~mm} \mathrm{Hg}$ (25 patients) (table $3)$, patients with a raised systemic venous pressure did not differ significantly from the other patients with regard to underlying cardiac malformation and associated anomalies, preoperative haemodynamic indices, or type of surgical procedure. Systemic venous pressure was related to age at evaluation $(P=0.036)$ and to systemic ventricular end diastolic pressure $(P=0.009)$. Predictors of postoperatively raised systemic venous pressure on stepwise logistic regression analysis were being older at operation and a preoperative pulmonary arteriolar resistance above $3 \mathrm{U} / \mathrm{m}^{2}$.

Postoperative cardiac index was not related to underlying intracardiac anatomy or to associated anomalies (table 4 ), but patients with a postoperative cardiac index $<31 / \mathrm{min} / \mathrm{m}^{2}$ had a higher incidence of left sided atrioventricular valve incompetence and a lower preoperative systemic blood flow $(P<0.001)$. These 
Table 3 Mean systemic venous pressure: preoperative, operative, and postoperative variables in 62 surviving patients

\begin{tabular}{|c|c|c|c|}
\hline & \multicolumn{2}{|c|}{ Mean systemic venous pressure } & \multirow[b]{2}{*}{$P$ value } \\
\hline & $\begin{array}{l}\leqslant 10 \mathrm{~mm} H g \\
(n=37)\end{array}$ & $\begin{array}{l}>10 \mathrm{~mm} H g \\
(n=25)\end{array}$ & \\
\hline \multicolumn{4}{|l|}{ Diagnosis: } \\
\hline TA & 5 & 5 & 0.590 \\
\hline $\begin{array}{l}\text { DIV } \\
\text { Complex SY }\end{array}$ & 8 & 7 & \\
\hline $\begin{array}{l}\text { Complex SV } \\
\text { Associated anomalies: }\end{array}$ & 24 & 13 & \\
\hline \multicolumn{4}{|l|}{$\begin{array}{l}\text { Associated anomalies: } \\
\text { Syst/pulm venous anomaly: }\end{array}$} \\
\hline Absent & 31 & 21 & 0.981 \\
\hline Present & 6 & 4 & \\
\hline \multicolumn{4}{|l|}{$A V$ valve abnormality: } \\
\hline Absent & 19 & 24 & 0.718 \\
\hline Present & 18 & 11 & \\
\hline \multicolumn{4}{|l|}{ Previous palliative procedures: } \\
\hline None & 12 & 3 & 0.065 \\
\hline Performed & 25 & 22 & \\
\hline \multicolumn{4}{|l|}{ Preoperative haemodynamic data: } \\
\hline Mean PA pressure (mm Hg) & $10 \cdot 83$ & $12 \cdot 04$ & $0 \cdot 208$ \\
\hline $\mathbf{R p}\left(\mathrm{U} / \mathrm{m}^{2}\right)$ & 1.65 & 1.93 & $0 \cdot 184$ \\
\hline $\mathrm{SV}$ end diast pressure $(\mathrm{mm} \mathrm{Hg})$ & 5.97 & 6.47 & 0.466 \\
\hline $\mathrm{Qp}\left(1 / \mathrm{min} / \mathrm{m}^{2}\right)$ & 3.74 & 3.68 & $0 \cdot 887$ \\
\hline Qs $\left(1 / \mathrm{min} / \mathrm{m}^{2}\right)$ & 3.73 & 3.41 & $0 \cdot 190$ \\
\hline Age at operation (months) & $61 \cdot 70$ & $82 \cdot 60$ & 0.095 \\
\hline \multicolumn{4}{|l|}{ Surgical technique: } \\
\hline Atriopulmonary anastomosis & 7 & 6 & 0.629 \\
\hline TCPÄ & 30 & 19 & \\
\hline \multicolumn{4}{|l|}{ Reoperation: } \\
\hline None & 27 & 19 & 0.587 \\
\hline Performed & 10 & 6 & \\
\hline Follow up (months) & $51 \cdot 83$ & $62 \cdot 88$ & 0.076 \\
\hline Age at evaluation (months) & $113 \cdot 54$ & $145 \cdot 56$ & 0.036 \\
\hline \multicolumn{4}{|l|}{ Postoperative haemodynamic data: } \\
\hline Interval (months) & $29 \cdot 56$ & 33.44 & 0.427 \\
\hline Mean PA pressure (mm Hg) & $8 \cdot 83$ & $12 \cdot 2$ & $<0.001$ \\
\hline SV end diastolic pressure (mm Hg) & $4 \cdot 38$ & $6 \cdot 48$ & 0.009 \\
\hline Qs $\left(1 / \mathrm{min} / \mathrm{m}^{2}\right)$ & $3 \cdot 29$ & 2.98 & $0 \cdot 128$ \\
\hline Arterial saturation (\%) & $93 \cdot 27$ & 93.69 & 0.695 \\
\hline \multicolumn{4}{|l|}{ Postoperative AV valve incompetence: } \\
\hline Absent & 20 & 14 & $0 \cdot 186$ \\
\hline Present & 17 & 11 & \\
\hline
\end{tabular}

DIV, double inlet ventricle; PA, pulmonary artery; Qp, pulmonary blood flow; Qs, systemic blood flow; $R p$, pulmonary arteriolar resistance; SV, single ventricle; Syst/pulm venous anomaly, systemic venous or pulmonary venous anomaly; TA, tricuspid atresia; TCPA, total cavopulmonary anastomosis.

Table 4 Postoperative cardiac index in relation to preoperative, operative and postoperative variables in 61 surviving patients

\begin{tabular}{|c|c|c|c|}
\hline & \multicolumn{2}{|c|}{ Cardiac index $\left(\mathrm{l} / \mathrm{min} / \mathrm{m}^{2}\right)$} & \multirow[b]{2}{*}{ Pvalue } \\
\hline & $\begin{array}{l}\leqslant 3 \\
(n=27)\end{array}$ & $\begin{array}{l}>3 \\
(n=34)\end{array}$ & \\
\hline \multicolumn{4}{|l|}{ Diagnosis: } \\
\hline TA & 7 & 3 & 0.172 \\
\hline DIV & 5 & 10 & \\
\hline Complex SV & 15 & 21 & \\
\hline \multicolumn{4}{|l|}{ Associated anomalies: } \\
\hline \multicolumn{4}{|l|}{ Syst/pulm venous anomaly: } \\
\hline Absent & 23 & 28 & 0.766 \\
\hline Present & 4 & 6 & \\
\hline \multicolumn{4}{|l|}{ AV valve abnormality: } \\
\hline Absent & 14 & 19 & 0.753 \\
\hline \multirow{2}{*}{\multicolumn{4}{|c|}{ Previous palliative procedures: }} \\
\hline & & & \\
\hline None & 8 & 7 & 0.415 \\
\hline Performed & 19 & 27 & \\
\hline \multicolumn{4}{|l|}{ Preoperative haemodynamic data: } \\
\hline Mean PA pressure $(\mathrm{mm} \mathrm{Hg})$ & $12 \cdot 11$ & $10 \cdot 58$ & $0 \cdot 106$ \\
\hline $\mathbf{R} \mathbf{p}\left(\mathrm{U} / \mathrm{m}^{2}\right)$ & 1.70 & $1 \cdot 8$ & 0.636 \\
\hline $\mathrm{SV}$ end diastolic pressure $(\mathrm{mm} \mathrm{Hg})$ & $6 \cdot 69$ & $5 \cdot 78$ & $0 \cdot 185$ \\
\hline $\mathrm{Qp}\left(1 / \mathrm{min} / \mathrm{m}^{2}\right)$ & $4 \cdot 17$ & $3 \cdot 38$ & 0.039 \\
\hline Qs $\left(1 / \min / \mathbf{m}^{2}\right)$ & $\begin{array}{r}3 \cdot 13 \\
85.25\end{array}$ & 3.98 & $<0.001$ \\
\hline \multicolumn{4}{|l|}{ Surgical technique: } \\
\hline Atriopulmonary anastomosis & 9 & 4 & 0.041 \\
\hline TCPA & 18 & 30 & \\
\hline \multicolumn{4}{|l|}{ Reoperation: } \\
\hline None & 18 & 28 & 0.062 \\
\hline Performed & 9 & 6 & \\
\hline Follow up (months) & $60 \cdot 85$ & $53 \cdot 29$ & $0 \cdot 227$ \\
\hline Age at evaluation (months) & $146 \cdot 14$ & $112 \cdot 73$ & 0.027 \\
\hline \multicolumn{4}{|l|}{ Postoperative haemodynamic data: } \\
\hline Interval (months) & $32 \cdot 40$ & 30.94 & 0.760 \\
\hline Mean PA pressure $(\mathrm{mm} \mathrm{Hg})$ & 10.62 & $9 \cdot 88$ & 0.208 \\
\hline Mean systolic venous pressure $(\mathrm{mm} \mathrm{Hg}$ ) & $10 \cdot 92$ & $10 \cdot 27$ & 0.340 \\
\hline SV end diastolic pressure $(\mathrm{mm} \mathbf{~ H g})$ & 5.96 & 4.67 & $0 \cdot 110$ \\
\hline Arterial saturation (\%) & 93.96 & 93.55 & 0.653 \\
\hline \multicolumn{4}{|l|}{ Postoperative $\mathrm{AV}$ valve incompetence } \\
\hline Absent & 13 & 21 & 0.272 \\
\hline Present & 14 & 13 & \\
\hline
\end{tabular}

AV, atrioventricular; diast, diastolic; DIV, double inlet ventricle; PA, pulmonary artery; $Q p$, pulmonary blood flow; $Q$ s, systemic blood flow; $R p$, pulmonary arteriolar resistance; syst systolic; SV, single ventricle; Syst/pulm venous anomaly, systemic venous or pulmonary venous anomaly; TA, tricuspid atresia; TCPA, total cavopulmonary anastomosis. patients were also older at operation and at postoperative evaluation. Using logistic regression analysis, only lower preoperative cardiac index and being older at operation were predictors of decreased cardiac index at rest.

\section{POSTOPERATIVE MORBIDITY}

Fifty three patients $(66 \%)$ were in sinus rhythm without any signs of rhythm disturbances on Holter ECG, including two of seven patients with atrial isomerism. Atrial arrhythmias defined as sinus node dysfunction $(\mathbf{n}=$ 7) and atrial tachyarrhythmias (including atrial flutter and supraventricular tachycardia in seven patients) were documented in $17 \%$ of the surviving patients (table 5). There was no significant relation to preoperative or postoperative haemodynamic data or surgical technique, but there was a correlation with the type of underlying cardiac malformation, with a higher proportion of arrhythmias in patients with tricuspid atresia $(P=0.009)$. Eleven patients had undergone pacemaker insertion for sinoatrial node dysfunction $(n=3)$, or preoperative $(n=4)$ or postoperative $(n=4)$ atrioventricular block.

Protein losing enteropathy was diagnosed in two of the 80 surviving patients, with peripheral oedema and ascites associated with hypoproteinaemia, lymphocytopenia, low immunoglobulin concentration, and abnormal $\alpha_{1}$-antitrypsin clearance. Diagnosis was made nine and 38 months after cavopulmonary anastomosis. In both patients, the systemic venous pressure at rest was increased to 14 and $16 \mathrm{~mm} \mathrm{Hg}$, respectively.

Intra-atrial thrombosis-as diagnosed on postoperative transthoracic echocardiograms-occurred in five patients $(6 \cdot 2 \%)$. Two of these patients developed acute symptoms, namely atrial tachyarrhythmias and acutely raised systemic venous pressure; both underwent surgical thrombectomy immediately after diagnosis. Three additional patients were clinically asymptomatic and the diagnosis of intraatrial thrombus was made on routine echocardiogram; they successfully underwent thrombolytic treatment. All five patients had undergone a total cavopulmonary anastomosis. Predisposing postoperative circumstances could be identified in all of them. In threewho had an early postoperative diagnosis of atrial thrombosis in spite of heparinisationthe thrombus was associated with mild obstruction at the cavopulmonary connection, with preoperatively raised pulmonary arteriolar resistance from general hypoplasia of peripheral pulmonary arteries, or postoperative immobilisation due to prolonged pleural

Table 5 Postoperative morbidity in 80 survivors

\begin{tabular}{lc}
\hline & Number of patients (\%) \\
\hline Arrhythmias: & \\
None & $53(66 \cdot 2 \%)$ \\
SND & $7(8 \cdot 8 \%)$ \\
SVT & $7(8 \cdot 8 \%)$ \\
Pacemaker & $11(13 \cdot 8 \%)$ \\
Protein losing enteropathy & $2(2 \cdot 5 \%)$ \\
Intra-atrial thrombus & $5(6 \cdot 2 \%)$ \\
\hline SND, sinoatrial node dysfunction; SVT, supraventricular
\end{tabular}
SND, sinoa
tachycardia. 
Table 6 Laboratory evaluation

\begin{tabular}{|c|c|c|c|c|}
\hline Variable & $\begin{array}{l}\text { Normal } \\
\text { value }\end{array}$ & $\begin{array}{l}\text { Number of } \\
\text { investigated } \\
\text { patients }\end{array}$ & Mean (SD) & $\begin{array}{l}\text { Number (\%) of } \\
\text { abnormal value }\end{array}$ \\
\hline Haemoglobin (g\%) & $<16$ & 55 & $14 \cdot 11(1 \cdot 4)$ & $5(9 \cdot 1)$ \\
\hline Factor II (\%) & 70 to 120 & 46 & $90 \cdot 13(14 \cdot 6)$ & $2(4 \cdot 3)$ \\
\hline Factor V (\%) & 65 to 120 & 45 & $77.88(18 \cdot 8)$ & $11(24 \cdot 4)$ \\
\hline Plasminogen (\%) & 70 to 120 & 40 & $91.47(19.3)$ & 0 \\
\hline AT III (\%) & 70 to 120 & 44 & $102.45(9.9)$ & 0 \\
\hline Protein C $(\%)$ & 65 to 120 & 43 & $70.55(13.0)$ & $11(25 \cdot 5)$ \\
\hline $\operatorname{TAT}(\mu g / 1)$ & $\leqslant 5.0$ & 37 & $9.46(15.3)$ & $10(27)$ \\
\hline Fragm $1+2(\mathrm{nmol} / \mathrm{l})$ & 0.1 to 1.2 & 42 & $0.62(0.3)$ & $1(2 \cdot 4)$ \\
\hline FBDP $(\mu \mathrm{g} / \mathrm{l})$ & $\leqslant 500$ & 43 & $248 \cdot 1(248)$ & $4(9 \cdot 3)$ \\
\hline Creatinine $(\mu \mathrm{mol} / \mathrm{l})$ & 57 to 90 & 51 & $44.45(11.6)$ & 0 \\
\hline AST (U/l) & 5 to 21 & 52 & $15 \cdot 3(3 \cdot 8)$ & 0 \\
\hline $\operatorname{ALT}(\mathrm{U} / \mathrm{l})$ & 5 to 21 & 51 & $12 \cdot 37(4 \cdot 0)$ & 0 \\
\hline CHE (kU/l) & 3.5 to 8.0 & 49 & $5.31(1.4)$ & $3(6 \cdot 1)$ \\
\hline $\mathrm{LDH}(\mathrm{U} / \mathrm{l})$ & 130 to 340 & 45 & $224 \cdot 5(54 \cdot 7)$ & $1(2 \cdot 2)$ \\
\hline $\mathrm{AP}(\mathrm{U} / \mathrm{l})$ & 110 to 600 & 47 & $366.44(153.4)$ & $3(6.4)$ \\
\hline$\gamma \mathrm{GT}(\mathrm{U} / \mathrm{l})$ & $<28$ & 50 & $24.9(15.8)$ & $19(38)$ \\
\hline Bilirubin $(\mu \mathrm{mol} / \mathrm{l})$ & $<18$ & 43 & $14 \cdot 25(7 \cdot 2)$ & $12(27 \cdot 9)$ \\
\hline Protein $(\mathrm{g} / \mathrm{l})$ & $>60$ & 50 & $66 \cdot 4(9 \cdot 2)$ & $12(24)$ \\
\hline Albumin $(\mathrm{g} / \mathrm{l})$ & $>35$ & 44 & $44 \cdot 84(6 \cdot 7)$ & $3(6 \cdot 8)$ \\
\hline Immunoglobulin (IgG) & Age related & 38 & Age related & $2(5 \cdot 3)$ \\
\hline
\end{tabular}

AP, alkaline phosphatase; ALT, alanine aminotransferase; AT III, antithrombin III; CHE, cholinesterase; CK, creatine kinase; FDBP, fibrin degradation products; Fragm 1+2, prothrombin fragment $1+2 ; \gamma \mathrm{GT}$, $\gamma$ glutamyltranspeptidase; LDH, lactate dehydrogenase; PTT, partial thromboplastin time; AST, aspartate aminotransferase; TAT, thrombin-antithrombin III complex.

effusion. Late postoperative atrial thrombosis was diagnosed on routine echocardiogram in two patients; both had previously developed signs of protein losing enteropathy but had normal protein $\mathrm{C}$ levels at time of thrombus diagnosis. Over a follow up of more than five years, $93.1 \%$ of the patients were free of atrial thrombosis.

Postoperative evaluation of organ function and various aspects of late postoperative problems require a detailed laboratory investigation as summarised in table 6 . In all patients this was performed more than one year (mean 45 (22.8) months, range 12 to 96 months) after the Fontan-type operation. Normal values of liver enzymes, antithrombin III, plasminogen, and protein $S$ concentrations, creatine kinase, and vitamin $A$ and $E$ levels were found in all cases. None of the patients had significant proteinuria $(>0.12 \mathrm{~g} / \mathrm{l})$. The main abnormal findings were increased $\gamma$-glutamyltranspeptidase in $38 \%$ and increased bilirubin concentrations in $28 \%$. Signs of mild cholestasis were more often found in patients who were older at the time of operation $(86.2$ (51) $v 61$ (36) months in patients without signs of cholestasis $(P=$ $0.05)$ ). With regard to postoperative haemodynamic data, two thirds of patients with cholestasis had a cardiac index less than $3 \mathrm{l} / \mathrm{min} / \mathrm{m}^{2}(P=0.045)$; in these patients the mean systemic venous pressure was also $>10$ $\mathrm{mm} \mathrm{Hg}(\mathrm{P}=0.05)$.

Hypoproteinaemia was found in 12 patients $(24 \%)$; three of these also had significant hypoalbuminaemia-including both the patients with protein losing enteropathy-confirmed by an increased $\alpha_{1}$-antitrypsin clearance. All 12 patients had undergone a total cavopulmonary anastomosis $(P<0.01)$ and their mean age at operation was less than those with normal protein concentrations (47 (45) $v$ 71 (40) months; $P=0.04$ ). There was no significant relation to preoperative morphological or haemodynamic criteria or to postoperative haemodynamic data.

Coagulation factor analysis excluded risk factors for thrombophilia in $75 \%$ of the patients investigated. Twenty five per cent were found to have a mild decrease of activated protein $C$ concentration (11 patients) or presented with pathological protein $\mathrm{C}$ resistance (four patients). Patients with anticoagulation treatment with warfarin had been excluded from postoperative coagulation system analysis. Patients with protein $\mathrm{C}$ deficiency had a lower mean serum protein level $(63.7, v 69.8 \mathrm{~g} / 1$ in patients with normal protein $C$ concentration; $P=0.046$ ). Signs of activation of the coagulation system (increased levels of thrombin-antithrombin III complex, prothrombin fragment $1+2$, and fibrin degradation products) were found in 15 patients. Postoperative routine echocardiography showed an intra-atrial clot (along the patch closure of the right sided atrioventricular valve) in only one of four patients with increased fibrin degradation products

Abnormal laboratory findings were not related to the follow up interval (more than or less than 36 months), and none of the variables except lymphocytopenia deviated further from the norm with longer follow up. None of the tested variables was correlated with postoperative systemic venous pressure. In patients with a cardiac index of more than $3 \mathrm{l} / \mathrm{min} / \mathrm{m}^{2}$, only the indices of cholestasis were significantly increased $(P=0.02)$.

\section{Discussion}

Functionally, the absence of a ventricular pumping chamber for the pulmonary circulation and an increase in systemic venous pressure are the main haemodynamic features after a Fontan procedure. In recent years the preferred type of anastomosis has changed from an atriopulmonary to a cavopulmonary anastomosis, with implantation of an intra-atrial polytetrafluorethylene tunnel patch. In these patients only a small part of the native right atrium is exposed to increased pressure, and the risk of postoperative arrhythmias is thought to be decreased. ${ }^{5-7}$ In addition, avoidance of turbulence within the systemic venous channel is expected to reduce the risk of postoperative thromboembolic events.

So far there are not sufficient data available to compare the haemodynamic results in patients after atriopulmonary anastomosis and total cavopulmonary anastomosis. In our study there was no significant difference between the two types of procedure with regard to postoperative mean systemic venous pressure. An increased systemic venous pressure was mainly associated with older age at operation and with preoperatively increased pulmonary arteriolar resistance, as shown before, ${ }^{24}$ but not with the underlying type of congenital heart defect or the early postoperative systemic venous pressure. For the whole patient group, the mean cardiac index was $3.1 \mathrm{l} / \mathrm{min} / \mathrm{m}^{2}$. Thus in comparison with the few other studies ${ }^{4}$ which include postoperative haemodynamic data, our results show relatively favourable postoperative haemodynamics at rest, although nearly two thirds of the patients presented preoperatively with associ- 
ated systemic and pulmonary venous anomalies or atrioventricular valve abnormalities.

\section{POSTOPERATIVE MORBIDITY}

Postoperative morbidity is mainly characterised by atrial arrhythmias, the occurrence of protein losing enteropathy, and intra-atrial thrombus. ${ }^{4-12}$

\section{Atrial tachyarrhythmias}

Atrial surgery, the number and course of atrial suture lines placed to create the intra-atrial tunnel, and an increase in mean systemic venous pressure might all be responsible for the $9-44 \%$ incidence of atrial tachyarrhythmias during the early and late postoperative period..$^{1314}$ The type of Fontan operation may be relevant for late atrial arrhythmias, and a lower incidence has been found in patients with total cavopulmonary anastomosis. ${ }^{15}$ Probably because of the small number of patients, we were unable to show this in our series. The overall incidence was not related to postoperative systemic venous pressure or to the cardiac index. The sinoatrial node dysfunction found in seven $(8 \cdot 7 \%)$ of our patients on postoperative 24 hour ECG, and in three patients who had already undergone pacemaker insertion for sinoatrial node dysfunction, explains the need for close follow up by Holter ECG in addition to electrophysiological investigations. ${ }^{41316}$

\section{Protein losing enteropathy}

Protein losing enteropathy after a Fontan procedure appears to be caused by intestinal lymphangiectasia secondary to chronically increased systemic venous pressure. ${ }^{17} 18$ In the early Fontan era, as well as in recent studies, approximately $10 \%$ of the long term survivors presented with this disorder. ${ }^{48}$ Only two of our patients $(2 \cdot 5 \%)$ developed clinical and laboratory signs of protein losing enteropathy; both these patients had a mean systemic venous and pulmonary artery pressure of $14 \mathrm{~mm} \mathrm{Hg}$. However, asymptomatic hypoproteinaemia and hypoalbuminaemia were observed in $24 \%$ and $7 \%$, respectively, suggesting a long term effect of even moderately increased systemic venous pressure. All these patients had undergone a total cavopulmonary anastomosis, suggesting some relation to the non-pulsatile, predominantly respiration dependent flow within the caval veins. There was no significant relation to the underlying cardiac malformation, or to preoperative or postoperative haemodynamic variables.

None of the patients had significant hepatocellular dysfunction, as shown by normal values of liver enzymes. Cholinesterase activity was only reduced in the two patients with clinically apparent protein losing enteropathy, due to intestinal losses. We found a relatively high incidence of mildly impaired excretory liver function postoperatively. There was a significant relation to mean age at operation and to the postoperative cardiac index, as well as to mean systemic venous pressure, but as described before ${ }^{8}$ there was no relation to duration of follow up.

\section{Atrial thrombus}

Partial atrial thrombosis was diagnosed by postoperative transthoracic echocardiography in five of our surviving patients $(6 \%)$. However, it seems that transoesophageal echocardiographic examination is more sensitive, especially in adolescent and adult patients. ${ }^{19} \mathrm{We}$ were able to identify predisposing haemodynamic abnormalities leading to venous stasis in all five patients. Additional factors predisposing to atrial thrombosis include arrhythmias, reduction of the transpulmonary gradient by restricted systemic ventricular function or atrioventricular valve incompetence, and a preoperative increase in pulmonary arteriolar resistance. ${ }^{40}$ In patients with increased risk of intra-atrial thrombus, prophylactic heparinisation during the early postoperative period is now followed by anticoagulation treatment with coumarins for at least three to six months postoperatively. The other patients receive aspirin for the same time period.

Coagulation factor abnormalities have already been described, being most frequent and most pronounced in association with protein $\mathrm{C}$ deficiency. ${ }^{821}$ Our analysis was mainly focused on the exclusion of risk factors for thrombophilia and venous thrombosis, as reflected by deficiency of protein $C$ and $S$ and antithrombin III, or pathological resistance to activated protein C. ${ }^{22}$ Abnormalities in these variables, in association with the special haemodynamic situation after a Fontan-type operation, would expose the patients to a high risk of thromboembolic complications and might indicate the need for vigorous anticoagulation treatment. Twelve of our patients $(25 \%)$ tested for coagulation factor abnormalities had a reduced protein $C$ concentration; in seven of these, this was associated with a more generalised reduction in serum proteins. Pathological resistance to activated protein $C$, as found in four patients, needs further investigation to establish the supposed underlying abnormality of factor $\mathrm{V}$ synthesis. ${ }^{22}$ Therefore a very detailed preoperative coagulation factor analysis should be performed in every patient to differentiate hereditary and potentially acquired coagulation factor abnormalities and to judge the postoperative risk of thromboembolic events.

To assess the postoperative activation of the coagulation system we measured the levels of thrombin-antithrombin III complex, prothrombin fragment $1+2$, and fibrin degradation products. ${ }^{23}$ Only one of the patients with abnormal values of these indices had evidence of atrial thrombus on a postoperative transthoracic echocardiogram. Four other patients with partial atrial thrombosis had normal values, although in a previous study the levels of thrombin-antithrombin III complex and prothrombin fragment $1+2$ appeared to correlate with potential thrombotic events in many situations. ${ }^{23}$ However, our observations suggest that thrombin-antithrombin III complex and prothrombin fragment $1+2$ values alone are unreliable for predicting potential subacute atrial thrombosis. 


\section{CONCLUSION}

In this intermediate follow up study we could not identify a constant laboratory pattern typical of patients after a modified Fontan operation. Except in the two patients with protein losing enteropathy, the documented abnormal findings did not have clinical manifestations. However, the high incidence of abnormal laboratory findings indicates the need for detailed postoperative surveillance, as further deterioration in organ function cannot be excluded.

1 Fontan F, Kirklin KW, Fernandez G, Costa F, Naftel DC, Tritto F, et al. Outcome after a "perfect" Fontan operaTritto F, et al. Outcome after a "p

2 Mayer JE, Bridges ND, Lock JE, Hanley FL, Jonas RA, Castaneda AR. Factors associated with marked reduction in mortality for Fontan operations in patients with single ventricle. F Thorac Cardiovasc Surg 1992;103:444-52.

3 Mair DD, Puga FJ, Danielson GK. Late functional status of survivors of the Fontan procedure performed during the 1970s. Circulation 1992;86(suppl II):106-9.

4 Driscoll DJ, Offord K, Feldt R, Schaff H, Puga FJ, Danielson GK. Five- to fifteen year follow-up after Fontan operation. Circulation 1992;85:469-96.

5 De Leval MR, Kliner P, Gewillig M, Bull C. Total cavopulmonary connection: a logical alternative to atriopulmonary connection for complex Fontan operations. $\mathcal{f}$ Thorac Cardiovasc Surg 1988;96:682-95.

6 Jonas RA. The importance of pulsatile flow when systemic venous return is connected directly to the pulmonary venous return is connected directly to the pulm
arteries. $\mathcal{F}$ Thorac Cardiovasc Surg 1993;105:173-5.

7 Jonas RA, Castaneda R. Modified Fontan procedure: atrial baffle and systemic venous to pulmonary artery anastobaffle and systemic venous to pulmonary artery

motic techniques. F Cardiac Surg 1988;3:91-6.
8 Cromme-Dijkhuis AH, Hess J, Hahlen K, Henkens CM, Bink-Boelkens MT, Eyegelaar AA, et al. Specific sequelae after Fontan operation at mid- and long-term followup. $\mathcal{F}$ Thorac Cardiovasc Surg 1993;106:1126-32.

9 Gewillig M, Wyse RK, de Leval MR, Deanfield JE. Early and late arrhythmias after the Fontan operation: predisposing factors and clinical consequences. Br Heart 7 1992;67:72-9.
10 Peters NS, Somerville J. Arrhythmias after the Fontan procedure. Br Heart $\mathcal{f}$ 1992;68:199-204.

11 Dobell ARC, Trusler GA, Smallhorn JF, Williams WG Atrial thrombi after the Fontan operation. Ann Thorac Surg 1986;42:664-7

12 Mahony L, Nikaidoh H, Fixler DE. Thrombolytic treatment with streptokinase for late intraatrial thrombosis after modified Fontan procedure. Am $\mathcal{F}$ Cardiol 1988;62 343-4.

13 Weber HS, Hellenbrand WE, Kleinman CS, Perlmutter RA, Rosenfeldt LE. Predictors of rhythm disturbances and subsequent morbidity after the Fontan operation. Am $\mathcal{F}$ Cardiol 1989;64:762-7.

14 Balaji S, Johnson TB, Sade RM, Case C, Gillette PC. Management of atrial flutter after the Fontan procedure. $\mathcal{F}$ Am Coll Cardiol 1994;23:1209-15.

15 Gelatt M, Hamilton RM, McCrindle BW, Gow RM Williams WG, Trusler GA, et al. Risk factors for atrial tachyarrythmias after the Fontan operation. $f \mathrm{Am}$ Coll tachyarrythmias after the

16 Mair DD, Hagler DJ, Puga FJ, Schaff HV, Danielson GK Fontan operation in 176 patients with tricuspid atresia: results and a new index for patient selection. Circulation 1990;82(suppl IV):164-9.

17 Hess J, Kruizinga $\mathrm{K}$, Bijleveld CMA, Hardjowijono $\mathrm{R}$ Eygelaar A. Protein-losing enteropathy after Fontan operation. $\mathcal{f}$ Thorac Cardiovasc Surg 1984;88:606-9.

18 Silverman A, Roy CC. Protein-losing enteropathy. In Silverman A, Roy CC, eds. Pediatric clinical gastroenterology, 3rd ed. St Louis: The CV Mosby Co, 1983:304-23.

19 Stumper O, Sutherland GR, Geuskens R, Roelandt JRTC, Bos E, Hess J. Transesophageal echocardiography in evaluation and management after Fontan procedure. $f$ Am Coll Cardiol 1991;17:174-81.

20 Hedrick M, Elkins RC, Knott-Craig CJ, Razook JD Successful thrombectomy for thrombosis of the right side of the heart after the Fontan operation. $f$ Thorac Cardiovasc Surg 1993;105:297-301.

21 Cromme-Dijkhuis AH, Henkens CMA, Bijleveld CMA, Hillege HL, Bom VJ, van der Meer J. Coagulation factor abnormalities as possible thrombotic risk factors after Fontan operation. Lancet 1990;336:1087-90.

22 Dahlback B. Inherited thrombophilia: resistance to activated protein $C$ as a pathogenic factor of venous thromboembolism. Blood 1995;85:607-14.

23 Hoek JA, ten Cate JW, Lamping J, Berends F, Borm JJ Laboratory and clinical evaluation of an assay of thrombin-antithrombin III complexes. Clin Chem 1988;34: 2058-62. 